taining a column of mercury, the rising and falling of which under influences of barometric pressure raised or lowered the centre of gravity of the pendulum and varied the rate of the clock accorlingly. The clock-train in both instruments was so arranged that the dial-readings could, by an exceedingly simple calculation, be interpreted in terms of mean daily thermometrical or barometricali variations. $\Lambda$ s the alteration in the lengths of the pendulums takes place second by second throughout the day, it follows that the daily error of time shown on the dial must be proportional to the mean of the variations of the thermometer or barometer during the same period.

The method of estimating, by observation of the rate of an uncompensated time-keeper, the mean amount of heat received during any given period, without the necessity of recording the actual temperature at any particular time, is not by any means new, for the chronometrical thermometer, an instrument which has for many years been emplnyed at the Royal Observatory for testing the rates of chronometers under variations of temperature, is founded upon the same principle. This instrument consists of a chronometer in which the usual compensation for temperature is reversed; that is to say, in the balance the positions of the brass and the steel are interchanged, the latter being outside, so that variations of temperature produce an exaggerated effect upon the rate of the instrument.

M. von Sterneck is probably the first to su'ggest the employment of the chronometrical method to the determination of mean variations in the vertical intensity of terrestrial magnetism, but he has, I think, been anticipated in its application to the computing of thermometric and barometric averages.

Sciestific Club, February 18

CONRAD W. COOKE

\section{BACTERIA IN WATER}

$\mathrm{I}^{\mathrm{T}}$ is weli known that water-whether tap or ordinary distilled-pussesses the property of contamiriating, with a growth of bacteria, any "cultivation" liquid" inoculated with it, but the morphological condition in which these organisms occur in it is open to question; it may be supposed on the one hand, that they exist as developed bacteria, and are not apparent under the microscope merely in consequence of their scarcity, as shown by Mr. Lister in the account of his recent admirable investigation of the lactic fermentation, to be the case with some specific ferments, or, on the other hand that they are present as "germs" of the bacteria, bodies yet far more minute than the mature forms, and on that account invisible-ultra-microscopic. Which of these alternatives is true I have endeavoured to determine by experiment, the details of which will shortly be published, and the general result is here briefly communicated.

M. Pasteur has recently stated in the Comptes Rendus that if a cylinder of water be allowed to stand for several weeks at a constant temperature, the organisms in it sink to the bottom, leaving the upper portion free, and incapable of contaminating. Following this method and placing a vessel of ordinary distilled water in an apparatus constructed for the purpose of maintaining an invariable temperature, after seven or eight days a specimen of the water was taken from the bottom of the vessel by a pipette closed with the finger and dipped into it. The water so taken was in appearance perfectly bright and pellucid, but under the microscope it was found to contain amorphous particles, some spores of filamentous fungi, micrococci in great numbers, bacteria of the common form (B. Termo) and bacilli (long and extremely slender filaments). All of these forms were motionless, or exhibited only Brownian movement. No such forms could be detected in the upper layers of the water, nor in a specimen taken from the bulk of that from which the experiments were made. As regards limpidity, there was no difference between the top and bottom portions.

I have made four experiments with specimens of water obtained from two different sources, and in all $I$ have been able by this method of subsidence to prove the presence of organisms in great numbers in the sediment. It may be mentioned that they stain with facility by
Hacmatoxylon, and are thereby rendered more readily apparent.

These observations show that bacteria occur in water under their usual forms, and that they are not generally distinguished on account of their small number, in any one portion of the water, when disseminated through its mass. The observed contaminating property of distilled water is thus accounted for without necessitating the assumption of "germs" of any sort, an hypothesis which is unsupported by observation.

The examination, by cultivation, of the difference in contaminating properties of the upper and lower layers, stated by M. Pasteur to exist, has as yet been inconclusive.

G. F. DOWDESWELL

\section{OUR ASTRONOMICAL COLUMN}

The Uranian Satellites, ARiel and Umbriel.The following positions of the two interior satellites of Uranus for the ensuing fortnight are derived from the data furnished by Mr. Marth in the January numiser of the Monthly Notices of the Royal Astronomical Society, and are for Irh. G.M.T., or about the time of the planet's meridian transit. There must be many telescopes in this country which will command the two exterior satellites, Titania and Oberon, but, so far as we know, neither Ariel nor Umbriel have yet been certainly observed here with any but Mr. Lassell's reflectors. Prof. Newcomb states that Ariel is intrinsically brighter than Umbricl; he thinks that Ariel at least belongs to that class of satellites of which the brilliancy is variable, and dependent on its position in its orbit, and he adds that the evidence of variability of some kind seems indisputable, since he has repeatedly failed to see it with the Washington refractor when the circumstances--distance from the primary not excepted-were favourable, and when the next satellite, Umbriel, though less favourably situated, was visible. "On the other hand," he remarks, "there were two occasions, I 874, January 28 , and I875, March 25, when it was surprisingly conspicuous," and at these times the angle of position was about $350^{\circ}$. Prof. Newcomb further expresses the opinion that where any difficulty is experienced in seeing the outer satellites, he would not hesitate to pronounce it impossible to see the inner ones.

Nevertheless, the success which has attended the search for one, at least, of the satellites of Mars by English observers who are provided with large instruments, may perhaps induce them to look for the close satellites of Uranus at the present opposition.
ArIEL.

\begin{tabular}{|c|c|c|c|c|c|}
\hline \multicolumn{2}{|c|}{ Feb. 22} & Pos & 179 & \multicolumn{2}{|c|}{ Dist. $13^{\prime \prime} 6$} \\
\hline , & 23 & ", & II & , & 15.1 \\
\hline & 24 & ", & 207 & ", & $11 \cdot 2$ \\
\hline " & 25 & ", & 77 & ", & $5^{2}$ \\
\hline$"$ & 26 & ", & $34^{\circ}$ & ", & $8 \% 7$ \\
\hline$"$ & 27 & ", & 181 & ", & $14^{\circ} 2$ \\
\hline & 28 & , & I3 & ", & 148 \\
\hline March & 1 & ", & 2 II & " & 102 \\
\hline " & 2 & " & 95 & $"$ & 49 \\
\hline " & 3 & " & 344 & $"$ & 98 \\
\hline " & 4 & ", & 183 & ", & $x_{4} \cdot 6$ \\
\hline ", & 5 & " & 15 & "? & 144 \\
\hline$"$ & 6 & " & 216 & 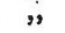 & $9^{\circ 2}$ \\
\hline$"$ & 7 & ", & II 2 & ", & $5^{\prime} \mathrm{I}$ \\
\hline
\end{tabular}

UMBRIEL.

\begin{tabular}{|c|c|c|}
\hline Po & 29 & Dist. \\
\hline ל, & 355 & " \\
\hline & 214 & $"$ \\
\hline & 178 & $"$ \\
\hline & 40 & ", \\
\hline & 웅 & ", \\
\hline & 228 & , \\
\hline & 183 & ", \\
\hline & 59 & " \\
\hline & 5 & ", \\
\hline & 253 & , \\
\hline & 187 & $"$ \\
\hline & 9 I & ", \\
\hline & 9 & ", \\
\hline
\end{tabular}

PIgOTT'S OBSERVATIONS OF VARIABLE STARS.-Some years since it was suggested, we believe, by. Prof. Argelander, that the Royal Society might have in its possession manuscripts of Edward Pigott of York, amongst which might be found observations of variable stars that would prove of importance in the history of their fluctuations. It would appear, however, that none of Pigott's papers are preserved in the Society's Archives, an ineffectual search having beẹn lately made for them. 